\title{
EFFECTS OF HUMANISTIC-EXISTENTIAL THERAPY ON SELF-CONTROL AMONG REHABILITATED FEMALE SEX WORKERS IN OSUN STATE
}

\author{
Adeola Shobola \\ Department of Educational Foundations and Counselling, \\ Faculty of Education, Obafemi Awolowo University, Ile-Ife, Nigeria
}

\begin{abstract}
The study determined the effect of Humanistic-Existential Therapy (HET) on self-control of rehabilitated female sex workers in Osun State and investigated the effect of demographic variables on the effectiveness of HET on the workers. The study adopted the pretest-posttest, control group quasi-experimental research design. The population comprised rehabilitated female sex workers who visited the Living Hope Care at Ilesa regularly for medical and sex guidance. The sample comprised 64 rehabilitated female sex workers selected from brothels in Osun State using purposive and convenient sampling techniques. The HET of Kirk Schneider (2008) treatment package used; while the Tangney, Baumeister, and Boone (2004) self-control was used. Data collected were analysed using percentage, counts, and Analysis of Covariance (ANCOVA).The results showed a significant effect of humanistic-existential therapy on the self-control of the participants at $(F=28.772, d f=1, p$-value $=0.000)$. It further showed the respondents' age $(F=1.229$, $d f=5$, p-value $=0.35)$, family background $(F=2.152, d f=1, p$-value $=0.166)$; while marital status $(F=$ 2.82, $d f=4$, p-value $=0.069$ ) had no significant simple moderating effect on the effectiveness of HET on the self-control of the participants. The study concluded that Humanistic-Existential Therapy was effective in treating self-control of the rehabilitated female sex workers.
\end{abstract}

\section{KEYWORDS}

Humanistic-Existential Therapy, Self-Control, Rehabilitated, Sex Workers

\section{INTRODUCTION}

Rehabilitation in any form is meant for correction and proper adjustment into a new way of life for an individual. It occurs only in situations where the formal way of life is detrimental to the individual and perhaps others around him/her. It could take place in the social, personal, financial, and career of an individual. Sex workers engage in the exchange of sexual activities for monetary gains. Engagement in sex work behaviour is not welcomed in some nations of the world especially in Nigeria, thus; some sex workers have been helped to withdraw from such an act.

Sex work is seemingly risky because at times the worker may experience ritual killing or attempt, being trafficked, and sexually abuse. The work also lacks a reliable future, therefore the government and non-governmental organisations have tried in some ways to rehabilitate the female sex workers by educating and engaging them in skill acquisitions such as tailoring, hairdressing, leatherwork, catering, just to mention a few. Also, the government and these 
organisations have helped in securing comfortable accommodations out of the brothels for some of the rehabilitated female sex workers. Some governments had also tried establishing some of the female sex workers by providing them with capital/money or soft loan as start-up capital for their businesses.

Despite all efforts of both the government and some NGOs to help the female sex workers, some rehabilitated female sex workers still fall back into sex work. The height of this is when rehabilitated female sex workers indulge in the work alongside their newly acquired skills. They call themselves 'Very Important Personnel' (VIP) sex workers since they have a well-paying job, and accommodation outside the brothel. Their mode of operation is to visit any party and present themselves well at such parties for rich men in the social party who may require their sex work services. Some others return to the brothels with the working tools given to them after the rehabilitation process to continue with sex work.

Some reasons have been posited to be responsible for female sex workers to re-enter sex work after being rehabilitated. Some of the reasons are that some female sex workers have high level of libido and their inability to control it. Therefore, there is the need to introduce psychological therapy to the female sex workers to help them develop a high level of self-control. This study therefore adopted humanistic-existential therapy of Kirk Schneider in treating self-control of the rehabilitated female sex workers.

Some other female sex workers find themselves in the act as a result of sexual abuse at an early age. Many of these girl/ladies are brought to the city with the mind of getting educated by going to school in order to secure a better future but only to be introduced to sex work by their masters/mistresses who bring them to the city. Having been exposed to sex work for a period of time and having internalised and adopted it as a way to live a comfortable life, it may become difficult to quit such practice even when they are being equipped with better life.

In some previous studies, in which counselling intervention was successfully applied to provide solutions to emotional and psychological problems that are related to self-control faced by or similar to those problems faced by rehabilitated female sex workers. For instance, Parrish, Standard, and Cobia, (2008) demonstrated that humanistic-existential therapy is useful in helping adolescents who exhibit inappropriate sexual behaviour since it addresses other underlining problems of mental health and emotional problems such as depression, trauma, behavioural disorders, and developmental deficits. Also, Jafari, Agbaei and Rashidi (2020), carried out a research on couples who were having marital challenges using humanistic-existential therapy as a therapeutic treatment and discovered that existential humanistic therapy was effective in improving their love attitude and search for meaning in life.

Despite the perceived effectiveness of humanistic-existential therapy, there is also a dearth of research-based evidence as regards its effectiveness in proffering psychological help to sex workers. In line with these, there is the need to investigate the effectiveness of the therapy on self-control of rehabilitated female sex workers also, to compare the effect of demographic variables on the therapy; hence this study.

\section{Purpose of The Study}

The purpose of the study was to examine the effects of humanistic-existential therapy on selfcontrol. Also to determine the efficacy of humanistic-existential therapy and by so doing, the therapy's efficacy in improving the self-control of female sex workers will be ascertained. The specific objectives of the study are to: 
(a) examine the effect of humanistic-existential therapy on self-control of the rehabilitated female sex workers; and

(b) investigate the effect of demographic variables (age, family background, marital status, socio-economic status, and level of formal education) on the effectiveness of humanisticexistential therapy on self-control of the rehabilitated female sex workers;

\subsection{Research Hypotheses}

The hypotheses are as follows:

1. There is no significant effect of humanistic-existential therapy on the self-control among rehabilitated female sex workers in Osun State; and

2. There is no significant effect of demographic variables (age, background, marital status, level of education) on the effectiveness of humanistic-existential therapy on the selfcontrol of rehabilitated female sex workers in the State.

\subsection{Research Design}

The research work was an experimental study adopting the pretest-posttest, control research design. The study sought to examine the effects of Humanistic Existential Therapy (HET) on the self-control of rehabilitated female sex workers in Nigeria. The study applied a counselling intervention on two separate but statistically identical groups of female sex workers as experimental and control groups. The statistical similarity among the groups of research participants was 50 rehabilitated female sex workers in each group to ensure baseline uniformity between and among the groups; therefore, ensuring no group had an undue advantage over the other before treatment.

\subsection{Sample and Sampling Techniques}

The sample consisted of one hundred (100) female sex workers selected based on purposive sampling technique (female sex workers who returned to the job having been trained in acquisition of skills) and this sample represented 50\% of the population of female sex workers that converged at Ilesa but lived in different towns within Osun State.

The female sex workers were consulted through the owner of Living Hope Care and their consent was sought to participate in the treatment programme. To participate in the study, the rehabilitated female sex workers were required to complete a questionnaire that was provided for them to identify their levels of self-control, and those willing to participate in the counselling treatment were selected using the purposive sampling technique. The 50 participants each were conveniently assigned into two groups making a total number of 100 participants in the experimental group and control group. The experimental group was subjected to HumanisticExistential Therapy. The Humanistic-Existential group was met at Ilesa, and the control group was met at Osogbo. The control group was subjected to a placebo treatment that involved training with no therapeutic effect on self-control and this was centred on discussions on skills acquired in the past.

\subsection{Research Instruments}

Two instruments titled 'Humanistic Existential Treatment Package', and 'Self-control of Rehabilitated Female Sex Workers Questionnaire' (SRFSWQ) were used to collect data for this 
study. The questionnaire had two sections consisting of Demographic variables, Self-Control Scale.

\subsection{Validation of Research Instrument}

The research instrument was given to experts in the departments of Psychology and Mental Health of the Obafemi Awolowo University. The experts having assessed all the items of the instrument in terms of language acceptability, relevance to the study and suitability for the respondents, all the comments and constructive criticisms passed on certain aspects of the instrument was duly noted and implemented during the reconstruction process. The instrument was also interpreted into Yoruba and Pidgin English Languages for the respondents to understand the contents of the questionnaire.

The instrument for the study was trial-tested with 30 sex workers in Lagos State and these were not part of the final sample of the study. The response from the administered questionnaire was subjected to factorial analysis for the construct validity of the instrument. To ascertain the usability of factorial validation for the items in each section of the questionnaire, Kaiser-MeyerOlkin (KMO) and Bartlett's Test of Sphericity (BTS) tests were carried out to ascertain the suitability of the items for factorial validation. The KMO value for section B was greater than the critical value at 0.05 level of significance. The Cronbach's Alpha approach was adopted in determining the reliability of the scale and yield 0.870

\subsection{Procedure for Data Collection}

The researcher gained access to the rehabilitated female sex workers through the Director of Living Hope Care. At the first meeting with the female sex workers, 200 female sex workers were in attendance out of which only 100 of them who had undergone rehabilitation were willing to be part of the therapeutic training. They were then divided into two groups of 50 participants each based on the town they reside in the State. The female sex workers in the experimental group consisted of sex workers in Ile-Ife and its environs. They were met at the Obafemi Awolowo University campus. While the control group consisted of sex workers in Osogbo and were met there. The researcher was assisted with the experimental group by two research assistants while the assistance of a social worker was sought for the control group in Osogbo. The meetings lasted six weeks for each of the groups and it was carried out simultaneously. At the end of the 6th week, the participants had reduced during the cause of the training to 31,33 for the experimental, and control groups respectively due to Covid-19 pandemic.

\section{ReSUlts}

Hypothesis one: There is no significant effect of humanistic-existential therapy on the selfcontrol among rehabilitated female sex workers in Osun State.

To test this research hypothesis, the pre-test and post-test computed self-control scores of participants who have been exposed to the humanistic-existential therapy and the control group were subjected to tests of difference using Analysis of Covariance (ANCOVA) with their pre-test scores as covariates. The experimental group exposed to the humanistic-existential therapy consisted of 31 participants while the control group consisted of 33 participants. The results of the descriptive statistics and ANCOVA are presented in Table 1. 
Table 1. Descriptive Statistics of pre-test and post-test scores obtained by participants exposed to the humanistic-existential therapy and control group

\begin{tabular}{llllll}
\hline & Pre-test & \multicolumn{5}{l}{ Post-test } \\
\hline Group & Mean & Std. Deviation & Mean & Std. Deviation & N \\
\hline EXPERIMENTAL & 76.16 & 6.2775 & 61.61 & 5.4017 & $\mathbf{3 1}$ \\
CONTROL & 77.85 & 10.8430 & 71.24 & 11.9296 & $\mathbf{3 3}$ \\
\hline
\end{tabular}

$* \mathrm{~N}=$ Sample Size

Table 1 reveals that the participants in the experimental group exposed to the humanisticexistential therapy have a pre-test mean score of $76.16 \pm 6.2775$ and a post-test score of $61.61 \pm 5.401$ while the participants in the control group have a pre-test mean score of $77.85 \pm 10.8430$ and a post-test score of 71.24 \pm 11.93 . Furthermore, the test of mean difference using Analysis of Covariance (ANCOVA) with their pre-test scores used as covariates is presented in Table 2.

Table 2. ANCOVA showing the effect of humanistic-existential therapy on self-control among rehabilitated female sex workers in Osun State

\begin{tabular}{|c|c|c|c|c|c|c|c|}
\hline \multicolumn{8}{|c|}{ Dependent Variable: Self-Control (Post-test) } \\
\hline Source & $\begin{array}{ll}\text { Type III } \\
\text { Sum } \\
\text { Squares }\end{array}$ & Df & Mean Square & $\mathrm{F}$ & p-value & $\begin{array}{l}\text { Partial } \\
\text { Squared }\end{array}$ & Eta \\
\hline Corrected Model & $4604.532^{\mathrm{a}}$ & 2 & 2302.266 & 60.873 & .000 & .666 & \\
\hline Intercept & 22.557 & 1 & 22.557 & .596 & .443 & .010 & \\
\hline $\begin{array}{l}\text { Self-Control } \\
\text { (pre-test) }\end{array}$ & 3122.338 & 1 & 3122.338 & 82.556 & .000 & .575 & \\
\hline Group & 1088.173 & 1 & 1088.173 & 28.772 & .000 & .320 & \\
\hline Error & 2307.077 & 61 & 37.821 & & & & \\
\hline Total & $\begin{array}{l}290601.00 \\
0\end{array}$ & 64 & & & & & \\
\hline $\begin{array}{l}\text { Corrected Total } \\
\text { a. } \mathbf{R} \text { Squared }=\end{array}$ & $\begin{array}{l}6911.609 \\
\text { Adjusted R }\end{array}$ & $\begin{array}{r}63 \\
\text { Squa }\end{array}$ & .655) & & & & \\
\hline
\end{tabular}

From Table 2, given that $\mathrm{F}=28.772$, $\mathrm{df}=1$, P-value $=0.000<0.05$, it showed that there is a significant effect of humanistic-existential therapy on the self-control among rehabilitated female sex workers. It was also observed that $66.6 \%$ of the variance in the participants' self-control is explained by this model. Hence, the null hypothesis was rejected and it was concluded that there is a significant effect of humanistic-existential therapy on the level of self-control among rehabilitated female sex workers in Nigeria.

Hypothesis Two: There is no significant moderating effect of demographic variables (age, family background, marital status) on the effectiveness of HET on the self-control of rehabilitated female sex workers in the State.

To test this research hypothesis, the pre-test and post-test computed self-control scores of participants who have been exposed to the humanistic-existential therapy and the control group was subjected to test of difference using Analysis of Covariance (ANCOVA) with their pre-test scores used as covariate and age, family background and marital status used as fixed factors. The results of the ANCOVA are presented in Table 3. 
International Journal of Education (IJE) Vol.9, No.4, December 2021

Table 3. ANCOVA showing the effect of demographic variables (age, family background) on the effectiveness of HET on self-control of rehabilitated female sex workers

\begin{tabular}{lllllll}
\hline Source & $\begin{array}{l}\text { Type III Sum } \\
\text { of Squares }\end{array}$ & Df & Mean Square & F & Sig. & $\begin{array}{l}\text { Partial } \\
\text { Squared }\end{array}$ \\
\hline Corrected Model & $6607.121^{\mathrm{a}}$ & 50 & 132.142 & 5.642 & .001 & .956 \\
Intercept & 24.189 & 1 & 24.189 & 1.033 & .328 & .074 \\
Pre-test & 750.261 & 1 & 750.261 & 32.032 & .000 & .711 \\
Group & 710.922 & 1 & 710.922 & 30.352 & .000 & .700 \\
Age & 143.910 & 5 & 28.782 & 1.229 & .350 & .321 \\
Family Type & 50.416 & 1 & 50.416 & 2.152 & .166 & .142 \\
Marital status & 264.221 & 4 & 66.055 & 2.820 & .069 & .465 \\
Group * Age & 188.012 & 5 & 37.602 & 1.605 & .227 & .382 \\
Group * Family Type & 1.878 & 1 & 1.878 & .080 & .782 & .006 \\
Group * Marital status & 51.142 & 4 & 12.786 & .546 & .705 & .144 \\
Age *amily Type & 213.877 & 4 & 53.469 & 2.283 & .116 & .413 \\
Age * Marital status & 141.138 & 6 & 23.523 & 1.004 & .463 & .317 \\
$\begin{array}{l}\text { Family Type * Marital } \\
\text { status }\end{array}$ & 290.522 & 3 & 96.841 & 4.135 & $\mathbf{. 0 2 9}$ & .488 \\
$\begin{array}{l}\text { Group * Age * Family } \\
\text { Type }\end{array}$ & 116.037 & 4 & 29.009 & 1.239 & .343 & .276 \\
Group * Age * Marital \\
status
\end{tabular}

From Table 3, age of respondents $(\mathrm{F}=1.229, \mathrm{df}=5, \mathrm{P}$-value $=0.35>0.05)$, Family background $(\mathrm{F}=2.152, \mathrm{df}=1, \mathrm{P}$-value $=0.166>0.05)$ and Marital status $(\mathrm{F}=2.82, \mathrm{df}=4, \mathrm{P}$-value $=0.069>$ $0.05)$ do not have a significant simple moderating effect on the effectiveness of HET on the selfcontrol of rehabilitated female sex workers. However, there existed a significant independent interaction effect of Family Type and Marital status $(\mathrm{F}=4.135$, df $=3$, P-value $=0.029<0.05)$ as well as a main interaction effect of Age and Marital status across groups $(F=3.027$, df $=6, \mathrm{P}$ value $=0.045<0.05$ ) on the effectiveness of HET on the self-control of rehabilitated female sex workers. Hence, the null hypothesis was rejected and it can be concluded that there is a significant moderating interaction effect of Age and Marital status on the effectiveness of HET on the self-control of rehabilitated female sex workers in the State.

\section{DisCuSSION OF FINDINGS}

The primary goal of this study was to determine the effect of humanistic-existential therapy on self-control among rehabilitated female sex workers. The result of the first research hypothesis showed that there is a significant difference between the post-test mean scores of the humanisticexistential group and the control group. This led to the conclusion that humanistic-existential therapy was effective in improving the self-control of rehabilitated female sex workers. Humanistic-existential therapy as a counselling technique has been widely used in the modernday counselling practice and proven effective in resolving diverse psychological problems ranging from drug and substance abuse, addiction, anxiety, neuroticism, depression, and suicidal ideation (O'Connor \& Chamberlain, 1996). Since some of these psychological issues are similar to those experienced by the rehabilitated female sex workers, it is therefore expected that 
humanistic-existential therapy will be efficiently helpful in improving their level of self-control; hence, the observed effects in its application. After therapy, rehabilitated female sex workers have a lower monetary expenditure associated with sexual dependent habits, a better quality of life, a greater sense of control over their addiction, and trust in their ability to sustain their rehabilitation. This is in line with some scientific discoveries about the effect of humanisticexistential therapy. According to Bauman and Kopp (2010), sex offenders are harshly critical of themselves, have a great deal of guilt and self-blame for their behaviour, and feel ostracized and branded by society because of this aspect of themselves. In the five years, Bauman and Kopp had been conducting this group; no member had re-offended to their knowledge after using the humanistic-existential therapy to treat the sex offenders. Quadland (1985) as cited by Klontz, Garos, and Klontz (2005), reported a noteworthy reduction in several areas of problematic sexual behaviors in the treatment group six months after treatment carried out among gay and bisexual men. While this is contrary to the finding of Wan, Finlayson, and Rowles (2000), who reported a high rate of relapse in some or all sexually dependent behaviours identified in treatment admitted on their clients. The therapy is an effective tool in treating self-control among rehabilitated female sex workers.

The second research hypothesis was there is no significant moderating effect of demographic variables (age, family background, marital status) on the effectiveness of HET on the self-control of rehabilitated female sex workers in the State. The respondents' age, family type, marital status does not have a significant simple moderating effect on the effectiveness of HET on the selfcontrol of rehabilitated female sex workers. However, there exists a significant independent interaction effect of family type and marital status, as well as a main interaction effect of age and marital status across groups on the effectiveness of HET on the self-control of rehabilitated female sex workers. Hence, the null hypothesis was rejected and it can be concluded that there is a significant moderating interaction effect of age and marital status on the effectiveness of HET on the self-control of rehabilitated female sex workers in the State.

\section{CONClusion}

The results obtained from this study established that Humanistic-Existential Therapy exerts a significant effect on the level of self-control of rehabilitated female sex workers in Osun State.

\section{Recommendations}

The following recommendations were made

1. Humanistic-Existential Therapy is a good therapy that can be used by any organisation rendering rehabilitation to maladaptive behaviour persons such as sexual disorders, addiction to drugs, and gambling, etc.

2. The government and NGOs as well as counsellors should make use of the information provided in this study to assist sex workers who are ready to quit the profession.

\section{REFERENCES}

[1] Bauman, S., \& Gregory Kopp, T. (2006). Integrating a humanistic approach in outpatient sex offender groups. The Journal for Specialists in Group Work, 31(3), 247-261.

[2] O’Connor, K., \& Chamberlain, K. (1996). Dimensions of life meaning: A qualitative investigation at mid-life. British Journal of Psychology, 87 (Pt 3), 461-477. doi: 10.111/j.2044-8295.1996.tb02602.x

[3] Parrish, M. S., Stanard, R. P., \& Cobia, D. C. (2008). Using existential-humanistic approaches in counselling adolescents with inappropriate sexual behaviours. Journal of Humanistic Counselling, Education \& Development, 47(1), 26-41. 
International Journal of Education (IJE) Vol.9, No.4, December 2021

[4] Quadland, M. C. (1985). Compulsive sexual behavior: Definition of a problem and an approach to treatment. Journal of Sex \& Marital Therapy, 11(2), 121-132.

[5] Schneider, K. (Ed.) (2008). Existential-integrative psychotherapy: Guideposts to the core of practice. New York: Routledge.

[6] Wan, M., Finlayson, R., \& Rowles, A. (2000). Sexual dependency treatment outcome study. Sexual Addiction \& Compulsivity: The Journal of Treatment and Prevention, 7(3), 177-196. 